\title{
IMRT WITH THE USE OF SIMULTANEOUS INTEGRATED BOOST IN TREATMENT OF HEAD AND NECK CANCER: ACUTE TOXICITY EVALUATION
}

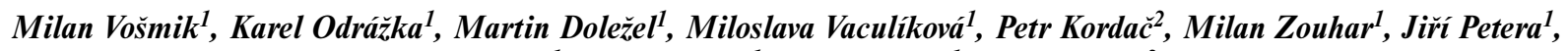 \\ Jan Jansa ${ }^{1}$, Zdeněk Zoul ${ }^{1}$, Petr Paluska ${ }^{1}$, Jan Vokurka ${ }^{2}$
}

Charles University in Prague, Faculty of Medicine and University Hospital in Hradec Králové, Czech Republic: Department of Oncology and Radiotherapy ${ }^{1}$; Department of Otolaryngology, Head and Neck Surgery ${ }^{2}$

Summary: Acute toxicity has been evaluated in head and neck cancer patients treated with intensity-modulated radiotherapy using simultaneous integrated boost (SIB-IMRT). The basis of the treatment protocol is an irradiation in 30 fractions with a total dose: $66 \mathrm{~Gy}$ to the region of macroscopic tumor, $60 \mathrm{~Gy}$ to the region of high-risk subclinical disease and 54 Gy to the region of low-risk subclinical disease. Between December 2003 and September 2005, 38 patients with carcinoma of different locations in the head and neck region were irradiated. Five patients underwent concurrent chemotherapy (weekly cisplatin). Acute toxicity was evaluated according to Radiation Therapy Oncology Group toxicity scale for skin, mucous membrane, salivary glands, pharynx and esophagus and larynx. All 38 patients completed the therapy without urgency of interruption due to acute toxicity of radiotherapy. No patient experienced grade 4 toxicity. More severe toxicity was observed in patients with concurrent chemotherapy. The results confirm that the irradiation according to our SIB-IMRT protocol is a therapy with acceptable toxicity and there is a space for radiobiological enhancement of this regimen by concurrent chemotherapy, e.g. weekly cisplatin.

Key words: Head and neck cancer; IMRT; Simultaneous integrated boost; Acute toxicity

\section{Introduction}

Radiotherapy (RT) plays an essential role in the management of head and neck cancer. In early stage lesions, radiotherapy can be preferred because it is as effective as surgery in controlling the disease and it has better cosmetic and functional outcome. In advanced stages, RT is used in the postoperative setting or as a primary curative treatment. In most cases, the irradiation should encompass both primary tumor (or tumor bed in postoperative setting) and regional lymphatic nodes.

Radiotherapy treatment planning in head and neck region is more complicated than RT in other regions, mainly due to many critical structures which are necessary to spare (spinal cord, brain stem, brain, optic nerves and chiasma, eyes, salivary glands etc.).

Intensity-modulated radiotherapy (IMRT) is a relatively new radiotherapy technique. It allows highly conformal dose distributions around tumor targets and sparing of the critical organs involved. Cancers in head and neck region became an ideal model for the application of IMRT. The possibility to spare eye bulbs, optic nerves and chiasma, brain stem and temporal lobes of brain dosimetrically fav- ours IMRT in nasopharyngeal, maxillary sinus and nasal cancers $(17,25)$. One of the main advantages of oropharyngeal, hypopharyngeal and laryngeal cancers is the possibility of parotid salivary glands sparing. There is already sufficient evidence of dosimetric and mainly clinical advantage of IMRT parotid sparing technique.

IMRT offers not only critical structures sparing, but also a dose escalation in regions with high risk of local recurrence (primary tumor or tumor bed) in each fraction. This principle is called simultaneuous integrated boost (SIB). There are many possible SIB fractionation regimens. Apparently, the most frequent regimen is 66 Gy in 30 fractions to the primary tumor region $(2.2 \mathrm{~Gy}$ per fraction, biological equivalent 70 Gy in conventional regimen 2 Gy per fraction), $60 \mathrm{~Gy}$ to the high-risk subclinical disease region (2.0 Gy per fraction, biological equivalent $60 \mathrm{~Gy}$ in conventional regimen) and $54 \mathrm{~Gy}$ to the low-risk subclinical disease region (1.8 Gy per fraction, biological equivalent 50 Gy in conventional regimen).

All patients treated at our department by intensity-modulated radiotherapy using simultaneuous integrated boost (SIB-IMRT) and fractionation mentioned above were identified with the aim of acute toxicity evaluation. 


\section{Materials and Methods}

\section{Patients}

Between December 2003 and September 2005, 41 patients started radiotherapy according IMRT-SIB protocol (regimen $66 \mathrm{~Gy}, 60 \mathrm{~Gy}$ and $54 \mathrm{~Gy}$ in 30 fractions) at our department. In three patients the treatment was terminated early. In one patient the IMRT was finished after few initial fractions due to necessity of urgent tracheostomy. The patient then completed radiotherapy by conventional technique and the cause of acute suffocation was not interpreted to be in relationship with radiotherapy. The two other patients refused to continue the radiotherapy after completing approximately half of the treatment sessions. Their acute toxicity evaluation did not exceed grade 2 in any organ. All three patients were excluded from acute toxicity evaluation.

All 38 patients included in evaluation had histological verified carcinoma (mostly squamous cell carcinoma) in the head and neck region and all patients had indications for irradiation of regional lymph nodes. Twenty six patients were irradiated with the primary curative intent, in twelve cases the radiotherapy was perfomed postoperatively due to positive or close histological margins. Five patients were treated by concurrent radiotherapy and chemotherapy (cisplatin $40 \mathrm{mg} / \mathrm{m}^{2}$ weekly). It is necessary to mention accidental treatment of other diseases, which certainly influenced acute toxicity of the patients. One patient was treated by imunosupressive therapy after kidney transplantation and one patient had a chronic therapy with low-dose metotrexate for gout in the first week of the radiotherapy. All patient and tumor characteristics are indicated in Tab. 1.

\section{Treatment planning and radiotherapy}

Two planning systems - CadPlan Treatment Planning System (Varian Medical Systems Inc., Palo Alto, USA) with Helios module for inverse planning and Eclipse (Varian Medical Systems Inc., Palo Alto, USA) were used. For defining of planning target volumes and organs at risk planning computer tomography with an application of contrast medium (if no contraindication), in some cases fusion with magnetic resonance, was used. During the treatment planning procedures and radiotherapy head and shoulders of patients were strictly immobilized by thermoplastic masks.

Gross tumor volume (GTV), clinical target volume (CTV) and planning target volumes (PTV) were defined according to the International Commission on Radiation Units and Measurements (ICRU) Report 50 reccommendation. PTV66 encompassed all macroscopic disease (= GTV) with a border (usually $1-2 \mathrm{~cm}$, minimally $0,5 \mathrm{~cm}$ ) for risk of microscopic spread (CTV) and set-up inaccuracies (PTV). PTV60 and PTV54 encompassed the regions (lymph nodes) with high risk and low risk of subclinical spread of the disease, recpectively. The following structures at risk were defined and contoured: spinal cord, spinal cord $+1 \mathrm{~cm}$ margin (for set-up inaccuracies risk), both parotid glands, brain stem and oral cavity and posterior neck region as help structures. In patients with primary tumor localizations near scull base (nasopharyngeal and maxillary sinus carci-

Tab. 1: Patient and tumor characteristics.

\begin{tabular}{|l|c|}
\hline Gender (n): & 32 \\
Male & 6 \\
Female & \\
\hline Age (y): & 55 \\
Median & $25-83$ \\
Range & \\
\hline Tumor site (n): & 13 \\
Oropharynx & 6 \\
Hypopharynx & 8 \\
Larynx & 5 \\
Nasopharynx & 4 \\
Maxillary sinus & 2 \\
Nasal cavity & 35 \\
\hline Histological type & 1 \\
Squamous cell carcinoma & 1 \\
Undifferentiated carcinoma & 1 \\
Adenocarcinoma & \\
Adenoid cystic carcinoma & 1 \\
\hline Tumor stage (n): & 7 \\
I & 11 \\
II & 19 \\
III & 21 \\
IV & 5 \\
\hline Radiotherapy (n): & 12 \\
RT alone & \\
Concurrent RT and CT & \\
Postoperative RT & \\
\hline
\end{tabular}

Abbreviations: $\mathrm{RT}=$ radiotherapy; $\mathrm{CT}=$ chemotherapy .

Tab. 2: Prescription doses for planning target volumes and tolerance doses for main organs at risk.

\begin{tabular}{|l|l|}
\hline Structure & Prescription \\
\hline PTV66 & $\begin{array}{l}\text { Minimally 95\% of prescribed } \\
\text { dose to 95\% of the volume }\end{array}$ \\
\hline PTV60 & $\begin{array}{l}\text { Maximal dose } \leq 15 \% \text { of } \\
\text { prescribed dose }\end{array}$ \\
\hline PTV54 & $\begin{array}{l}\text { EUD } \\
\text { to the prescribed dose }\end{array}$ \\
\hline Spinal cord & $\begin{array}{l}\text { GTV is in minimally 95\% } \\
\text { isodose }\end{array}$ \\
\hline Spinal cord + margin 1 cm & Maximum dose <44 Gy \\
\hline Brain stem & Maximum dose <50 Gy \\
\hline Parotid glands & $\begin{array}{l}\text { Minimally } 50 \% \text { of gland } \\
\text { volume dose <30 Gy or } \\
\text { mean dose <28 Gy }\end{array}$ \\
\hline $\begin{array}{l}\text { Larynx (if it is not a part } \\
\text { of PTV) }\end{array}$ & 2/3 below 50 Gy \\
\hline
\end{tabular}

Abbreviations: PTV - planning target volume. 
nomas) eye bulbs, optic nerves and chiasma were also defined. Prescription doses for PTVs and tolerance doses for organs at risk are shown in Tab. 2. It is necessary to point out that not all these demands could be fulfilled in all patients. For example, when macroscopic tumor was close to organ at risk (primary oropharyngeal tumor or lymphadenopathy close to parotid gland etc.), a compromise had to be chosen. The equivalent uniform dose for PTVs was calculated according Niemierko with parametr $\mathrm{a}=-8$ (21).

$$
E U D=\left(\sum_{i=1}^{N} v_{i} D_{i}^{a}\right)^{1 / a}(1)
$$

All patients were irradiated on linear accelerator Clinac 600C (Varian Medical Systems Inc., Palo Alto, USA) with dynamic multileaf colimator ( $2 \times 26$ leafs). The prescribed physical doses were delivered in 30 equivalent fractions in 6 weeks.

\section{Acute toxicity evaluation}

The patients were minimally once a week examined by a physician during the treatment. Acute toxicity was evaluated according to the RTOG (Radiation Therapy Oncology Group) toxicity scale for skin, mucous membrane, salivary glands, pharynx and esophagus and larynx (Tab. 3).

Tab. 3: RTOG acute toxicity criteria.

\begin{tabular}{|c|c|c|c|c|c|}
\hline organ & Grade 0 & Grade 1 & Grade 2 & Grade 3 & Grade 4 \\
\hline SKIN & $\begin{array}{l}\text { No } \\
\text { change } \\
\text { over } \\
\text { baseline }\end{array}$ & $\begin{array}{l}\text { Follicular, faint or dull } \\
\text { erythema/ epilation/dry } \\
\text { desquamation/ } \\
\text { decreased sweating }\end{array}$ & $\begin{array}{l}\text { Tender or bright } \\
\text { erythema, patchy moist } \\
\text { desquamation/ moderate } \\
\text { edema }\end{array}$ & $\begin{array}{l}\text { Confluent, moist } \\
\text { desquamatiom other } \\
\text { than skin folds, pitting } \\
\text { edema }\end{array}$ & $\begin{array}{l}\text { Ulceration, } \\
\text { hemorrhage, } \\
\text { necrosis }\end{array}$ \\
\hline $\begin{array}{l}\text { MUCOUS } \\
\text { MEM- } \\
\text { BRANE }\end{array}$ & $\begin{array}{l}\text { No } \\
\text { change } \\
\text { over } \\
\text { baseline }\end{array}$ & $\begin{array}{l}\text { Injection/ may } \\
\text { experience mild pain not } \\
\text { requiring analgesic }\end{array}$ & $\begin{array}{l}\text { Patchy mucositis which } \\
\text { may produce an } \\
\text { inflammatory serosangu- } \\
\text { initis discharge/ may } \\
\text { experience moderate } \\
\text { pain requiring analgesia }\end{array}$ & $\begin{array}{l}\text { Confluent fibrinous } \\
\text { mucositis/ may include } \\
\text { severe pain requiring } \\
\text { narcotic }\end{array}$ & $\begin{array}{l}\text { Ulceration, } \\
\text { hemorrhage or } \\
\text { necrosis }\end{array}$ \\
\hline $\begin{array}{l}\text { SALIVARY } \\
\text { GLAND }\end{array}$ & $\begin{array}{l}\text { No } \\
\text { change } \\
\text { over } \\
\text { baseline }\end{array}$ & $\begin{array}{l}\text { Mild mouth dryness/ } \\
\text { slightly thickened saliva/ } \\
\text { may have slightly altered } \\
\text { taste such as metallic } \\
\text { taste/ these changes not } \\
\text { reflected in alteration in } \\
\text { baseline feeding } \\
\text { behavior, such as } \\
\text { increased use of liquids } \\
\text { with meals }\end{array}$ & $\begin{array}{l}\text { Moderate to complete } \\
\text { dryness/ thick, sticky } \\
\text { saliva/ markedly altered } \\
\text { taste }\end{array}$ & $\longrightarrow$ & $\begin{array}{l}\text { Acute salivary } \\
\text { gland necrosis }\end{array}$ \\
\hline $\begin{array}{l}\text { PHARYNX } \\
\& \text { ESO- } \\
\text { PHAGUS }\end{array}$ & $\begin{array}{l}\text { No } \\
\text { change } \\
\text { over } \\
\text { baseline }\end{array}$ & $\begin{array}{l}\text { Mild dysphagia or } \\
\text { odynophagia/ may } \\
\text { require topical } \\
\text { anesthetic or non- } \\
\text { narcotic analgesics/ may } \\
\text { require soft diet }\end{array}$ & $\begin{array}{l}\text { Moderate dysphagia or } \\
\text { odynophagia/ may } \\
\text { require narcotic } \\
\text { analgesics/ may require } \\
\text { puree or liquid diet }\end{array}$ & $\begin{array}{l}\text { Severe dysphagia or } \\
\text { odynophagia with } \\
\text { dehydration or weight } \\
\text { loss }(>15 \% \text { from pre- } \\
\text { treatment baseline) } \\
\text { requiring N-G feeding } \\
\text { tube, I.V. fluids or } \\
\text { hyperalimentation }\end{array}$ & $\begin{array}{l}\text { Complete } \\
\text { obstruction, } \\
\text { ulceration, } \\
\text { perforation, } \\
\text { fistula }\end{array}$ \\
\hline LARYNX & $\begin{array}{l}\text { No } \\
\text { change } \\
\text { over } \\
\text { baseline }\end{array}$ & $\begin{array}{l}\text { Mild or intermittent } \\
\text { hoarseness/cough not } \\
\text { requiring antitussive/ } \\
\text { erythema of mucosa }\end{array}$ & $\begin{array}{l}\text { Persistent hoarseness } \\
\text { but able to vocalize/ } \\
\text { referred ear pain, sore } \\
\text { throat, patchy fibrinous } \\
\text { exudate or mild } \\
\text { arytenoid edema not } \\
\text { requiring narcotic/ } \\
\text { cough requiring } \\
\text { antitussive }\end{array}$ & $\begin{array}{l}\text { Whispered speech, } \\
\text { throat pain or referred } \\
\text { ear pain requiring } \\
\text { narcotic/ confluent } \\
\text { fibrinous exudate, } \\
\text { marked arytenoid edema }\end{array}$ & $\begin{array}{l}\text { Marked } \\
\text { dyspnea, } \\
\text { stridor or } \\
\text { hemoptysis } \\
\text { with } \\
\text { tracheostomy } \\
\text { or intubation } \\
\text { necessary }\end{array}$ \\
\hline
\end{tabular}




\section{Results}

All 38 patients finished the therapy without the need of interruption due to acute toxicity. No patient experienced unacceptable grade 4 toxicity. We registered even acceptable grade 3 toxicity in 2 patients $(5.3 \%)$ in skin toxicity evaluation, in 11 patients $(28.9 \%)$ in mucouse membrane toxicity evaluation, in 14 patients $(36.8 \%)$ in pharyngeal toxicity evaluation, and in 1 patient $(2.6 \%)$ in laryngeal toxicity evaluation. More severe toxicity was observed in patients with concurrent chemotherapy, in patient treated by imunosupressive therapy and in patient treated with low-dose metotrexate in the first week of the radiotherapy, however grade 3 toxicity at most. Grade 3 acute hypopharyngeal/oesophageal toxicity was classified mainly due to weight loss and severe dysphagia with the necessity of parenteral rehydratation. The mucous mebrane acute reactions grade 3 were higher in subgroup with concurrent chemotherapy as expected: mucous membrane toxicity in $5 / 5$ patients $(100 \%)$ and pharyngeal/ oesophageal toxicity in $4 / 5$ patients $(80 \%)$, but the number of patients in this subgroup is too small for larger statistical analysis. All acute toxicity data are shown in Tab. 4.

Tab. 4: Acute toxicity evaluation according to RTOG scale - absolute number of patients (in curves - number of patients with concurrent chemotherapy).

\begin{tabular}{|l|c|c|c|c|c|}
\hline Organ & $\begin{array}{c}\text { Grade } \\
0\end{array}$ & $\begin{array}{c}\text { Grade } \\
1\end{array}$ & $\begin{array}{c}\text { Grade } \\
2\end{array}$ & $\begin{array}{c}\text { Grade } \\
3\end{array}$ & $\begin{array}{c}\text { Grade } \\
4\end{array}$ \\
\hline SKIN & 0 & $24(1)$ & $12(4)$ & $2(0)$ & 0 \\
\hline $\begin{array}{l}\text { MUCOUS } \\
\text { MEMBRANE }\end{array}$ & 0 & $4(0)$ & $23(0)$ & $11(5)$ & 0 \\
\hline $\begin{array}{l}\text { SALIVARY } \\
\text { GLAND }\end{array}$ & 0 & $15(0)$ & $23(5)$ & - & 0 \\
\hline $\begin{array}{l}\text { PHARYNX \& } \\
\text { ESOPHAGUS }\end{array}$ & 0 & $10(0)$ & $14(1)$ & $14(4)$ & 0 \\
\hline LARYNX & 0 & $21(1)$ & $16(3)$ & $1(1)$ & 0 \\
\hline
\end{tabular}

\section{Discussion}

The standard of radiotherapy of head and neck cancer is still conventional or conformal radiotherapy with the use of conventional fractionation regimen ( 2 Gy per fraction). In locally or locoregionally advanced lesions there are two main ways to improve treatment results of RT in curative setting: first is an alteration of fractionation regimen and second is a use of concurrent chemotherapy. The radiobiological enhancement by an alteration of fractionation regimen can be based on a compression of overall treatment time, as e.g. in Dahanca 6,7 trials (22), or a hyperfractionation or a combination of both (accelerated hyperfractionation eventually the use of concomitant boost technique). In all these approaches the locoregional control and survival were significantly improved in comparison to conventional regimen, although there is a higher risk of late effects in some of these regimens $(2,5,14)$.
The second possibility to enhance the effect of radiotherapy is the concurrent chemotherapy (CT). There are many chemotherapy regimens used as concurrent $\mathrm{CT}$, in most cases they are based on cisplatin. In a large meta-analysis reported, Pignon et al analysed data from 10471 patients treated between 1965-1993 in 63 randomised trials. The improvement of overall survival was noted only in concurrent combination of chemotherapy and radiotherapy but not in patients treated with neoadjuvant or adjuvant CT. The absolute survival benefit of concurrent CT was $8 \%$ in this meta-analysis (23). The update of the meta-analysis, by adding to the data base the data from the randomized trials performed between 1994 and 2000, was presented in 2004 at ASCO Annual Meeting by Bourhis et al (4). The absolute benefit of concurrent CT was still $8 \%$ in overall survival, but the magnitude of the benefit was significantly higher for platinum-based CT than for other CT. The highest benefit was noted in cisplatin alone - $11 \%$ (although there was no statistical significance compare to cisplatin poly-CT). The benefit of concurrent CT was noted over the last years in randomized trials with altered regimens of radiotherapy (6) and also in postoperative setting $(3,9)$.

The intensity-modulated radiotherapy has been introduced to the clinical practice approximately in the half of the last decade. IMRT is considered to be very effective and perspective radiotherapy technique, but this method is considered to be still experimental in many cases. The dosimetric advantage of IMRT is a possibility to spare organs at risk better than in conventional and conformal RT, mainly in concavities of PTV. Many authors prefer IMRT in nasopharyngeal cancer due to a concave shape of region of primary tumor. There are also many data about better postRT parotid gland function (and better quality of life) when parotid glands sparing approach is used $(1,8,12,18,26)$. The sparing of parotids is now one of the main reasons for an IMRT use in head and neck cancer.

Another important advantage of the IMRT is a possibility of planned dose inhomogennity in PTV - a possibility of simultaneous integrated boost. The advocates of SIBIMRT techniques emphasize a better conformality of irradiation in comparison to shrinking volumes technique $(11,20,26)$. Radiobiological comparison of several SIBIMRT regimens was elaborated by Mohan et al (20).

There are few publications as single institutions experiences with the use SIB-IMRT technique $(16,27)$. But there is no standard for fractionation scheme, there is no standard for IMRT planning, for normalization of a plan and many other controversies. The multicentric phase II trial RTOG H-0022 uses fractionation scheme 66 Gy - 60 Gy $54 \mathrm{~Gy}$ in 30 fractions for oropharyngeal cancer stage T1-2N0-1M0. The protocol specifies the prescription dose as the dose that encompasses at least $95 \%$ of the PTV, no more than $1 \%$ of the PTV can recieve < $93 \%$ of the prescribed dose and no more than $20 \%$ of the PTV can receive $>110 \%$ of the presribed dose (28). The phase II RTOG trial 0025 for nasopharyngeal cancer used radiotherapy or con- 


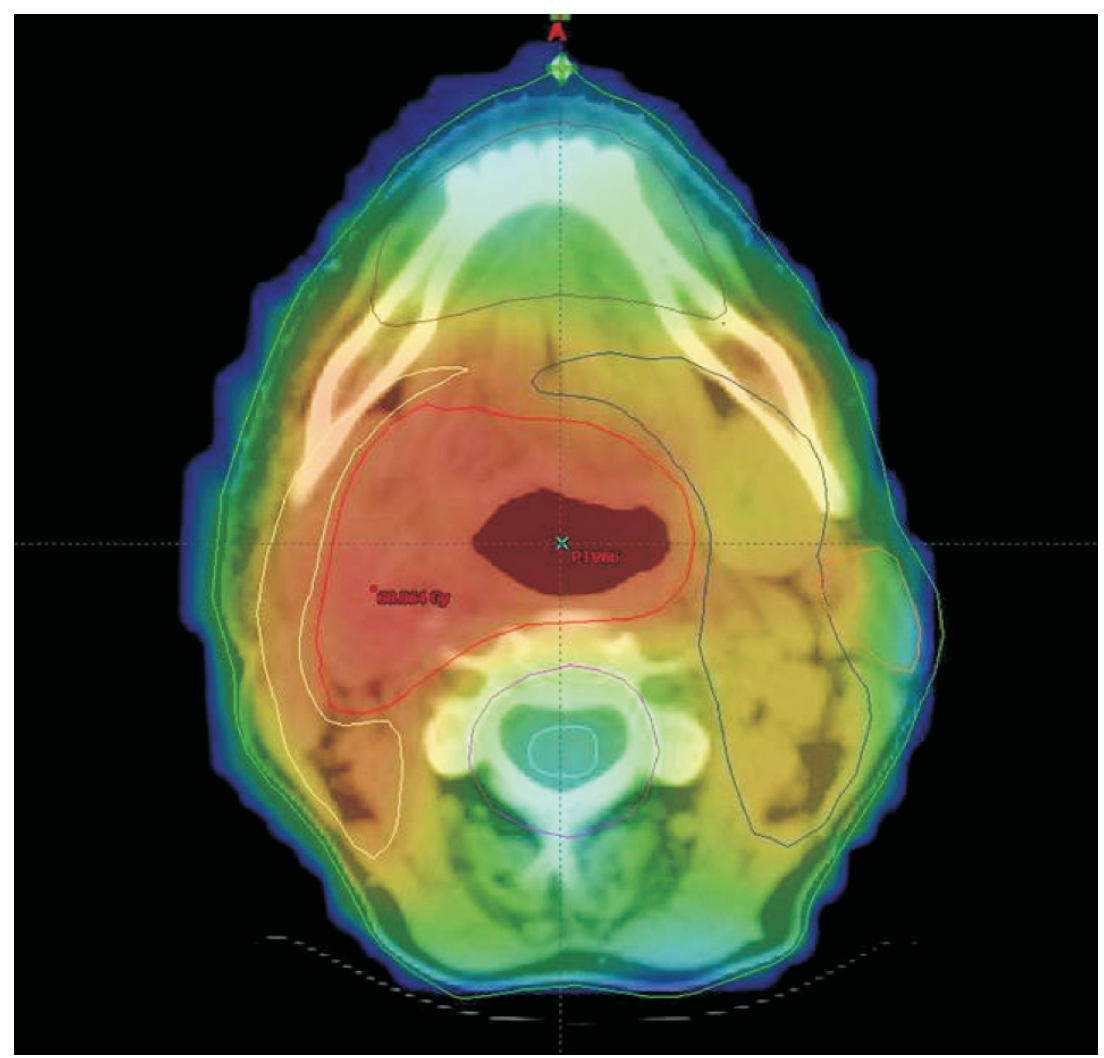

Fig. 1: IMRT-SIB technique (PTV66 - red contour, PTV60 - yellow contour, PTV54 - blue contour).

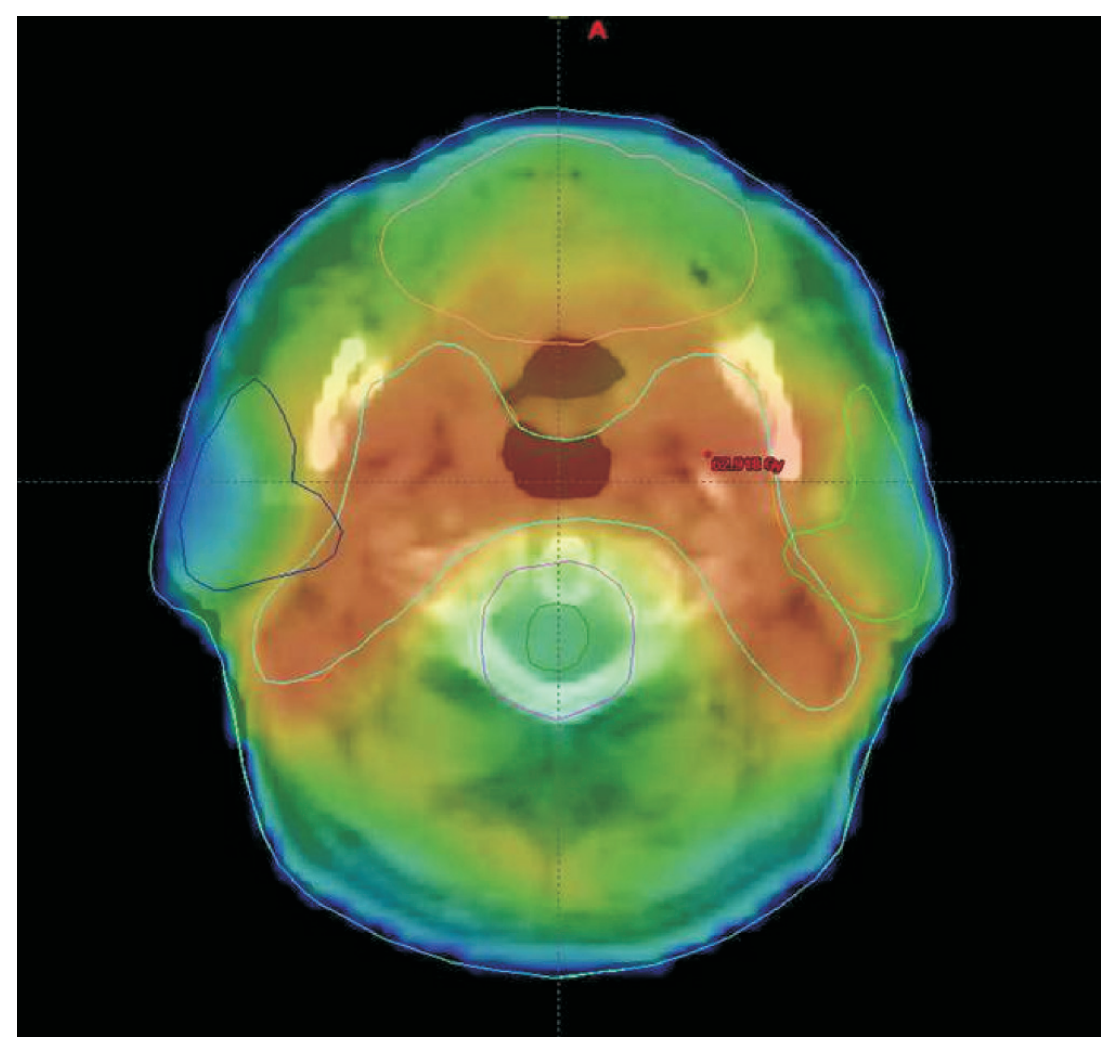

Fig. 2: Sparing of parotid glands by IMRT technique. 
current chemoradiotherapy (stage $\geq \mathrm{T} 2 \mathrm{~b}$ or node positive) with doses $70 \mathrm{~Gy}-59.4 \mathrm{~Gy}-50.4 \mathrm{~Gy}$ in 33 fractions and similar reccommendations for target coverage (29). In Europe there is a generraly accepted rule that $95 \%$ (instead of $100 \%$ ) of the PTV volume has to recieve $95 \%$ of the dose (10). A reason behind this practice is an application of „more real“ prescription doses when calculate an equivalent uniform doses according to Niemierko. In the case of the mentioned RTOG studies practice the EUD (PTV) as well as the PTV main dose has to be higher then the prescribed dose. This practice may be considered to be unacceptable because of the dose unequality with convetional plans prepared according to ICRU recommendations.

The present cohort of 38 patients with head and neck cancer with evaluated acute toxicity was treated by SIBIMRT technique with fractionation regimen $66 \mathrm{~Gy}-60 \mathrm{~Gy}$ - 54 Gy in 30 fractions. The biological equivalent doses in conventional fractinations are $70 \mathrm{~Gy}, 60 \mathrm{~Gy}$ and $50 \mathrm{~Gy}$ (20). Because of this, the regimen cannot be accepted as full-featured for curative RT of locoregionally advanced head and neck cancer. There are three possibilites to enhance effects of radiotherapy. The most common practice is to use a higher dose than $66 \mathrm{~Gy}$ in 30 fractions (70 Gy or more) $(15,16,27)$. On the other hand, there are data that dose escalation is tolerability limiting in acute reactions (15), and there is now limited evidence the higher dose per fraction cannot increase the late effect probability. Second option is an alteration of the regimen, e.g. the use of hyperfractionation. At our department we started a clinical trial with hyperfractionated SIB-IMRT regimen. In convetional RT there is now widely accepted standard - the use of concurrent chemotherapy. We suppose the concurrent chemotherapy will become standard also in SIB-IMRT practice.

The risk of acute toxicity grade $3-4$ in conventional fractionations is in various studies $25-50 \%$ (24). The alteration of fractionation causes higher incidence of mucosal reactions and in some cases the acute toxicity was the cause of discontinuation of clinical studies (13). Similarly, the limit of the chemotherapy enhanced radiotherapy is the acute toxicity, mainly in CT enhanced altered radiotherapy regimens, where grade 3-4 mucosal toxicity can reach $100 \%$ (19). There are some data of possible worseness of late toxicity in connection with the concurrent CT (7) but we suppose the late toxicity is in connection with a severe acute mucosal toxicty.

As our department shifts the practice to chemotherapy enhanced SIB-IMRT in locoregionally advanced head and neck cancers in terms of an initiating of a clinical trial we prepared the evaluation of the acute toxicity of head and neck cancer patients treated by the same regimen. Although the cohort is heterogenous group of patients in terms of primary tumor locality, stage of the disease and radiotherapy approach (primary versus postoperative RT, concurrent $\mathrm{CT}$ ), results of the evaluation confirm a feasibility of this regimen in patients with head and neck cancer, as well as in five patients with concurrent CT. The chronic toxicity evaluation of the cohort will be continously elaborated in next months.

Our results confirm that intensity-modulated radiotherapy with the simultaneous integrated boost and fractionation $66 \mathrm{~Gy}, 60 \mathrm{~Gy}$ and $54 \mathrm{~Gy}$, respectively, in 30 fractions is well-tolerated treatment. Acceptable tolerance of the treatment in patients treated by concurrent administration of weekly ciplatin suggests a potential of this regimen for other tumor localizations in head and neck region then nasopharynx. Complete evaluation of the therapeutic regimen requires longer follow-up and evaluation of chronic toxicity and locoregional control of the disease and overall survivall.

\section{Acknowledgements}

The study is supported in part by Charles University Grant Agency, Czech Republic (137/2004 C) and by Internal Grant Agency of the Ministry of Health, Czech Republic (NR 8061-3/2004).

\section{References}

1. Amosson CM, Teh BS, Van TJ et al. Dosimetric predictors of xerostomia for head-and-neck cancer patients treated with the smart (simultaneous modulated accelerated radiation therapy) boost technique. Int J Radiat Oncol Biol Phys 2003;56:136-44

2. Baumann M, Bentzen SM, Ang KK. Hyperfractionated radiotherapy in head and neck cancer: a second look at the clinical data. Radiother Oncol 1998; 46:127-130.

3. Bernier J, Domenge C, Ozsahin M et al. European Organization for Research and Treatment of Cancer Trial 22931. Postoperative irradiation with or without concomitant chemotherapy for locally advanced head and neck cancer. N Engl J Med 2004;350:1945-52.

4. Bourhis J, Amand C, Pignon JP, on behalf of the MACH-NC Collaborative Group. Update of MACH-NC (Meta-Analysis of Chemotherapy in Head \& Neck Cancer) database focused on concomitant chemoradiotherapy. J Clin Oncol 2004;22 (Suppl.): 5505 .

5. Bourhis J, Syz N, Overgaard J et al. Conventional vs modified fractionated radiotherapy, meta-analysis of radiotherapy in head \& neck squamous cell carcinoma: a meta-analysis based on individual patient data abstract Int J Radiat Oncol Biol Phys 2002;54 (Suppl 1):71-72.

6. Budach V, Stuschke M, Budach W et al. Hyperfractionated accelerated chemoradiation with concurrent fluorouracil-mitomycin is more effective than dose-escalated hyperfractionated accelerated radiation therapy alone in locally advanced head and neck cancer: final results of the radiotherapy cooperative clinical trials group of the German Cancer Society 95-06 Prospective Randomized Trial. J Clin Oncol 2005;23:1125-35.

7. Calais G. Late toxicity in patients treated with concurrent chemotherapy and radiotherapy for head and neck cancers Radiother Oncol 2004;73(Suppl.1): S71.

8. Chao KS, Deasy JO, Markman J et al. A prospective study of salivary function sparing in patients with head-and-neck cancers receiving intensity-modulated or three-dimensional radiation therapy: initial results. Int J Radiat Oncol Biol Phys 2001;49:907-16.

9. Cooper JS, Pajak TF, Forastiere A, et al. Precisely defining high-risk operable head and neck tumors based on RTOG \#85-03 and \#88-24: targets for postoperative radiochemotherapy? Head Neck 1998;20:588-94.

10. de Kruijf WJM, Heijmen BJM,Voet P,van der Est H, Levendag PC. The importance of the low-dose part (D smaller than 95\%) of the PTV-DVH in head and neck IMRT. Radiother Oncol 2004;73 (Suppl. 1), S89.

11. Dogan N, King S, Emami B et al. Assessment of different IMRT boost delivery methods on target coverage and normal-tissue sparing. Int $\mathrm{J}$ Radiat Oncol Biol Phys 2003;57:1480-91.

12. Eisbruch A, Ten Haken RK, Kim HM, Marsh LH, Ship JA. Dose, volume, and function relationships in parotid salivary glands following conformal and intensity-modulated irradiation of head and neck cancer. Int J Radiat Oncol Biol Phys 1999;45:577-87.

13. Fowler JF, Harari PM, Leborgne F, Leborgne JH. Acute radiation reactions in oral and pharyngeal mucosa: tolerable levels in altered fractionation schedules. Radiother Oncol 2003;69:161-168. 
14. Horiot JC, Bontemps P, van den Bogaert W et al. Accelerated fractionation (AF) compared to conventional fractionation $(\mathrm{CF})$ improves loco-regional control in the radiotherapy of advanced head and neck cancers: results of the EORTC 22851 randomized trial. Radiother Oncol 1997;44:111-21.

15. Lauve A, Morris M, Schmidt-Ullrich R et al. Simultaneous integrated boost intensity-modulated radiotherapy for locally advanced head-and-neck squamous cell carcinomas: II-clinical results. Int J Radiat Oncol Biol Phys 2004;60: 374-87.

16. Lee N, Xia P, Fischbein NJ, Akazawa P, Akazawa C, Quivey JM. Intensity-modulated radiation therapy for head-and-neck cancer: the UCSF experience focusing on target volume delineation. Int J Radiat Oncol Biol Phys 2003;57:49-60.

17. Lee N, Xia P, Quivey JM et al. Intensity-modulated radiotherapy in the treatment of nasopharyngeal carcinoma: an update of the UCSF experience. Int J Radiat Oncol Biol Phys 2002;53:12-22.

18. Lin A, Kim HM, Terrell JE, Dawson LA, Ship JA, Eisbruch A. Quality of life after parotid-sparing IMRT for head-and-neck cancer: a prospective longitudinal study. Int J Radiat Oncol Biol Phys 2003;57:61-70.

19. Maguire PD, Meyerson MB, Neal CR et al. Toxic cure: Hyperfractionated radiotherapy with concurrent cisplatin and fluorouracil for Stage III and IVA headand-neck cancer in the community. Int J Radiat Oncol Biol Phys 2004;58: 698-704.

20. Mohan R, Wu Q, Manning M, Schmidt-Ullrich R. Radiobiological considerations in the design of fractionation strategies for intensity-modulated radiation therapy of head and neck cancers. Int J Radiat Oncol Biol Phys 2000;46:619-30.
21. Niemierko A. A generalized concept of equivalent uniform dose (abstract). Med Phys 1999;26:1100.

22. Overgaard J, Hansen HS, Specht L et al. Five compared with six fractions per week of conventional radiotherapy of squamous-cell carcinoma of head and neck: DAHANCA 6 and 7 randomised controlled trial. Lancet 2003;362:933-40.

23. Pignon JP, Bourhis J, Domenge C, Designe L. Chemotherapy added to locoregional treatment for head and neck squamous-cell carcinoma: three meta-analyses of updated individual data. MACH-NC Collaborative Group. Meta-Analysis of Chemotherapy on Head and Neck Cancer. Lancet 2000;355:949-955.

24. Trotti A. Toxicity in head and neck cancer: a review of trends and issues. Int J Radiat Oncol Biol Phys 2000;47:1-12.

25. Sultanem K, Shu HK, Xia P et al. Three-dimensional intensity-modulated radiotherapy in the treatment of nasopharyngeal carcinoma: the University of California-San Francisco experience. Int J Radiat Oncol Biol Phys 2000;48: $711-22$

26. Wu Q, Manning M, Schmidt-Ullrich R, Mohan R. The potential for sparing of parotids and escalation of biologically effective dose with intensity-modulated radiation treatments of head and neck cancers: a treatment design study. Int J Radiat Oncol Biol Phys 2000;46:195-205.

27. Yao M, Dornfeld KJ, Buatti JM et al. Intensity-modulated radiation treatment for head-and-neck squamous cell carcinoma - the University of Iowa experience. Int J Radiat Oncol Biol Phys 2005;63:410-421.

28. http://www.rtog.org/members/protocols/h0022/h0022.pdf

29. http://www.rtog.org/members/protocols/0225/0225.pdf

Submitted August 2006 Accepted September 2006.

Milan Vošmik M.D., University Hospital in Hradec Králové, Department of Oncology and Radiotherapy, Sokolská 581, Hradec Králové, Czech Republic, e-mail: vosmik@fnhk.cz 